.

\title{
Microstructure and Mechanical Properties of Spray Formed and Hot-Pressed Hypereutectic Al- Si Alloy
}

\author{
Alawandi MR, Khaji SS and Dayanand M Goudar* \\ Department of Mechanical Engineering, India
}

ISSN: 2576-8840

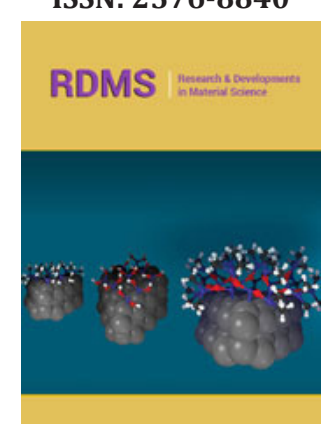

*Corresponding author: Dayanand M Goudar, Department of Mechanical Engineering, India

Submission: 面 June 19, 2019

Published: 海眥June 24, 2019

Volume 11 - Issue 1

How to cite this article: Alawandi MR, Khaji SS, Dayanand M G. Microstructure and Mechanical Properties of Spray Formed and Hot-Pressed Hypereutectic Al-Si Alloy. Res Dev Material Sci. 11(1). RDMS.000755.2019.

DOI: 10.31031/RDMS.2019.11.000755

Copyright@ Dayanand M Goudar, This article is distributed under the terms of the Creative Commons Attribution 4.0 International License, which permits unrestricted use and redistribution provided that the original author and source are credited.

\begin{abstract}
The microstructure and mechanical properties of spray formed and hot-pressed Al-35Si alloy was studied and compared with as cast alloy. The microstructures of spray deposited, hot pressed and as cast alloys were investigated by optical microscopy, scanning electron microscopy techniques. The microstructure of spray deposited alloy showed a homogeneous distribution of fine primary silicon, eutectic silicon phases in the equiaxed Al-matrix. The microstructural refinement was further increased by hot compression. The microstructure of as-cast alloy composed of coarse plate-like primary Si particles and needle/fiber form of eutectic Si randomly distributed in the Al dendritic matrix. Room temperature hardness and tensile strength of spray formed, hot compressed alloy showed considerable increase in their strength and ductility over that of as cast alloy. The improvement in hardness, mechanical properties of spray deposited alloy is discussed in light of the microstructural refinement induced during spray deposition and hot-pressing processes.
\end{abstract}

Keywords: Microstructure; Hardness; Tensile strength; Spray deposition process

\section{Introduction}

Hypereutectic Al-Si alloy is being used in the automobile industry and in other fields where high wear resistance, high specific stiffness; thermal stability and excellent dimensional stability are required. Typical uses of hypereutectic Al-Si alloys are pistons, cylinder liners, piston rings, connecting rods, pump and hydraulic components. Since Si immensely improves the wear resistance of these alloys because of its high hardness, it has been concluded that higher Si content leads to better wear resistance [1]. Silicon also improves the flowability of $\mathrm{Al}-\mathrm{Si}$ alloys due to its high latent heat of fusion and increases the fluidity of the melt due to release of considerable amount of heat during solidification. Increasing the Si content above eutectic composition causes the formation of coarse, irregular block like or platelike morphologies of primary Si particulates with a large aspect ratio and needle or fibrous forms of eutectic Si phase. The presence of non-uniformly distributed coarse Si particulates is generally thought to be responsible for the inherent brittleness and poor workability of conventional casted hypereutectic Al-Si alloys. The macro-segregated block / plate of primary Si particles in the matrix results in inferior mechanical properties and wear behavior and poor machinability [2]. Alloy with a uniform distribution of primary silicon particles have higher strength and better wear resistance. It has been reported that the size and shape of primary $\mathrm{Si}$ phase is dominantly affected by the cooling rate during solidification. Higher the cooling rate, finer will be the microstructure. The spray atomization and deposition is a rapid solidification process, also known as spray forming has attracted considerable interest as a viable process for manufacturing of alloys, composites and structural materials with the benefits associated with the rapid solidification such as fine grained microstructure, increased solid solubility, fine primary and secondary phases $[3,4]$. Hence, the products have enhanced material properties viz, strength, wear resistance and ductility. The spray forming process essentially involves atomization and deposition where molten metal having sufficient superheat is disintegrated into a spray of micron sized droplets by a high energy inert gas jet and the droplets are forced to reconsolidate on a conductive stationary or movable substrate held at a pre-determined distance below the atomizer to provide a coherent, nearly dense and near net shape perform. The objective of the present paper was to study the microstructure and mechanical properties of spray deposited and hot pressed of Al-Si alloy compared with as cast alloy. 


\section{Experimental}

In the present investigation the binary Al-35Si alloy of was prepared by spray forming process. The composition of the alloy was anlalysed by spark emission spectrometer [PAN analyticalXRD \& XRF Instrumentation, Model QSN 750-II single or multi matrix system].the nominal chemical composition of alloy is shown in the Table1.The details of the spray deposition process has been described elsewhere [5]. The melt was atomized by $\mathrm{N}_{2}$ with free fall type atomizer. An atomizer-copper substrate distance of $390 \mathrm{~mm}$ and delivery tube diameter of $4.00 \mathrm{~mm}$ were used. The details of the process parameters employed used in the present investigation is shown in the Table 2.

Table 1: Nominal chemical composition (wt.\%) Al-35Si Alloy.

\begin{tabular}{|c|c|c|c|c|c|c|c|}
\hline Alloy & Si & Fe & Mn & Mg & Cu & Ni & Al \\
\hline Al-35\%Si & 35 & 1.5 & 0.06 & 0.24 & 0.06 & -- & Bal \\
\hline
\end{tabular}

Table 2: Process variables employed in spray deposition study.

\begin{tabular}{|c|c|}
\hline Melt superheat & $1120{ }^{\circ} \mathrm{C}$ \\
\hline Melt flow & $2.5 \mathrm{~kg} / \mathrm{min}$ \\
\hline Gas pressure & $0.65 \mathrm{Mpa}$ \\
\hline Diameter of nozzle & $4 \mathrm{~mm}$ \\
\hline Deposition distance & $390 \mathrm{~m}$ \\
\hline Atomising gas & Nitrogen \\
\hline
\end{tabular}

The finite amount of porosity was invariably present in the spray deposited alloy. Samples were cut from the central region of the deposit to prepare specimen of size $100 \times 30 \times 20 \mathrm{~mm}$. The spray deposited alloy was hot pressed at a pressure of 55MPa and a temperature of $480{ }^{\circ} \mathrm{C}$. The hot pressing was carried out using 100-tonne hydraulic press. These tests were carried out at a crosshead speed of $0.5 \mathrm{~mm} / \mathrm{min}^{-1}$ which corresponds to a nominal strain rate of $0.05 \mathrm{~min}^{-1}$. The microstructure of the as-cast, spray deposited (SD), spray deposited and hot compressed (SD+HP) samples prepared using standard metallographic techniques of grinding on emery paper with $1 / 0,2 / 0,3 / 0$ and $4 / 0$ specifications. Final polishing was done on a wheel cloth using brasso and kerosene. The polished samples were etched with Keller's reagent (1\% vol. hydrofluoric acid, $1.5 \%$ vol. hydrochloric acid, $2.5 \%$ vol. nitric acid and rest water).

The microstructures of samples were examined under a ZEISS Optical Microscope. Grain size measurement is carried out using image analysis following the procedure discussed in ASTM E-112-96 (ASTM, 2003) [6].The microstructure, fracture surface of the tensile specimens samples were examined on SEM (Model: JEOL JSM$6480 \mathrm{LV}$ ) using secondary electron (SE) and backscattered electron (BSE) imaging modes. The chemical compositions of the constituent present in phases were examined using an energy dispersive X-ray (EDX) micro-analyzer. The SEM was operated at an acceleration voltage of 10-30kV. Micro hardness measurements were carried out on the as-cast, SD+HP alloys using Vickers hardness tester (Model: MVH, Meta-tech Industries, India). Hardness measurements were carried out using an indentation load of $300 \mathrm{~g}$ and allowing a dwell time of 15 seconds for each indentation. Each micro-hardness value reported in the present work is an average value of five readings. Standard tensile test specimens were prepared from the as-cast, SD+HP alloys were tested in tension following the ASTME-8 standard (ASTM, 2000). Surface of the specimens were polished using fine abrasive of $0.025 \mu \mathrm{m} \mathrm{Al}_{2} \mathrm{O}_{3}$ powder emulsion in water. The specimens were tested till fracture using an INSTRON Universal Testing Machine at room temperature and elongation was measured with a static axial clip on extensometer (Model: Instron, Strain gauge type, 2630-102). These tests were carried out at a crosshead speed of $0.0083 \mathrm{mms}^{-1}$ which corresponds to a nominal strain rate of $0.05 \mathrm{~min}^{-1}$. Three tensile test specimens were prepared, the test data reported was the average of three

\section{Results and Discussion}

\section{Microstructural analysis}
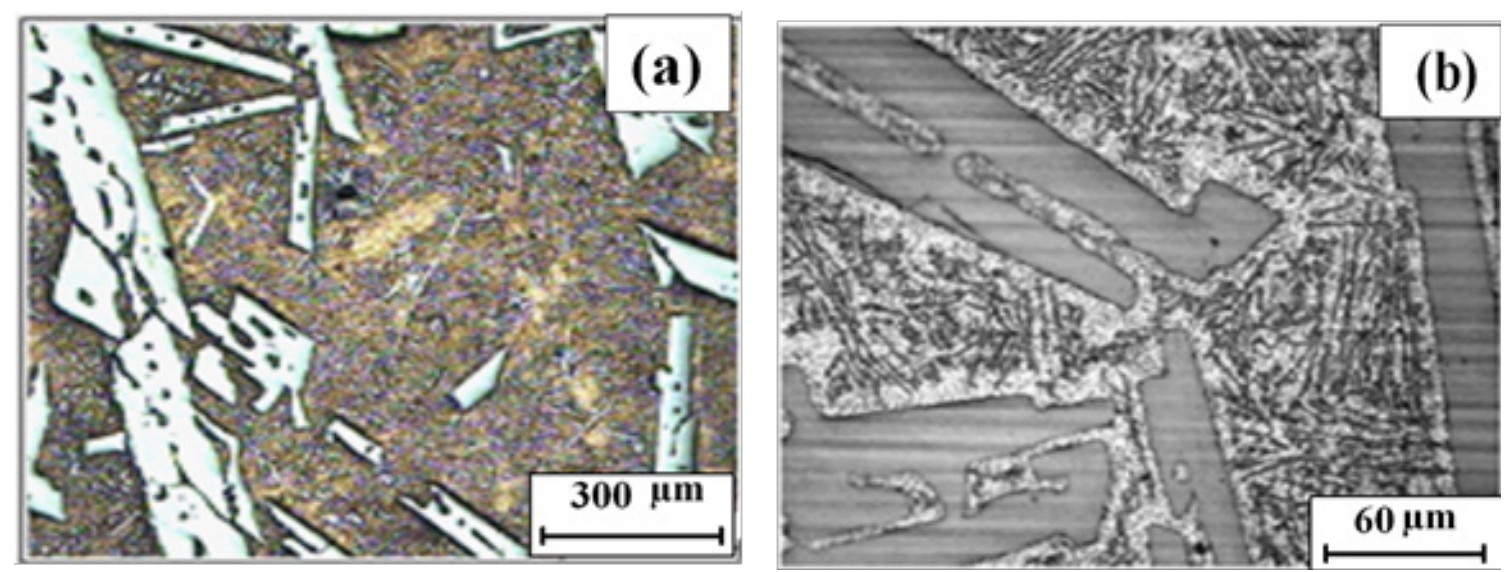

Figure 1: (a) Optical micrograph of as-cast Al-35Si alloy (b) higher magnification showing the dendrite A-Si eutectic phase. 

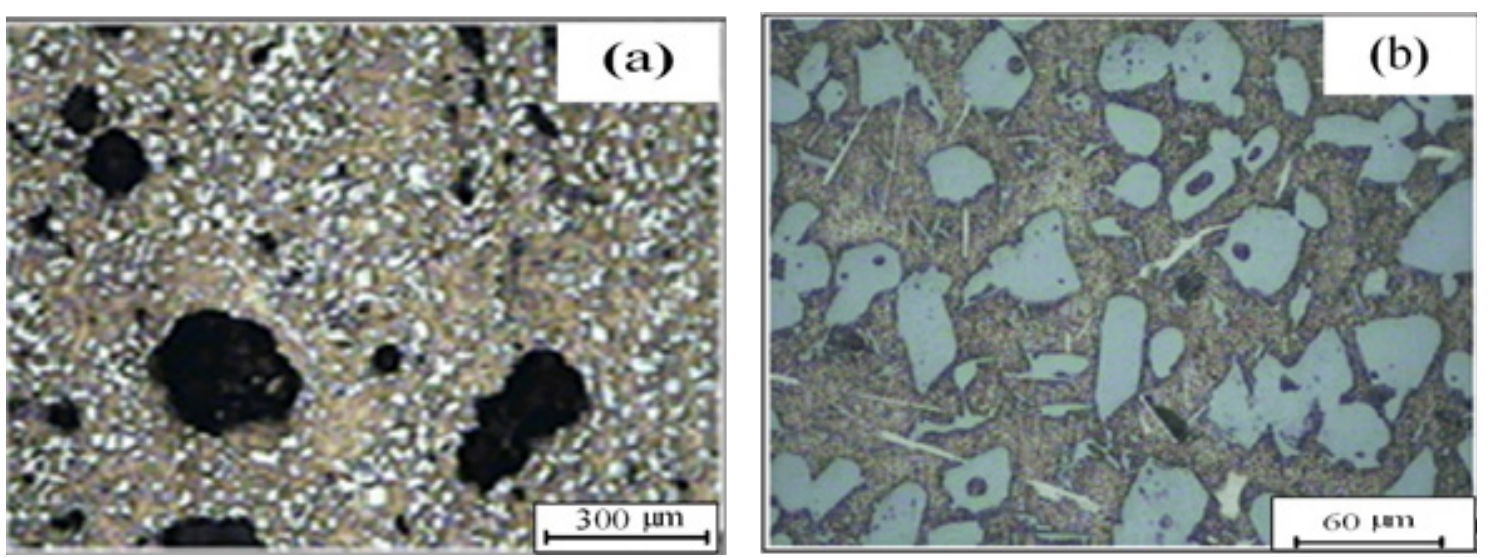

Figure 2: (a) Optical micrograph of SD Al-35Si alloy (b) higher magnification showing the shape and size of primary Si and Al-S-Fe phases.
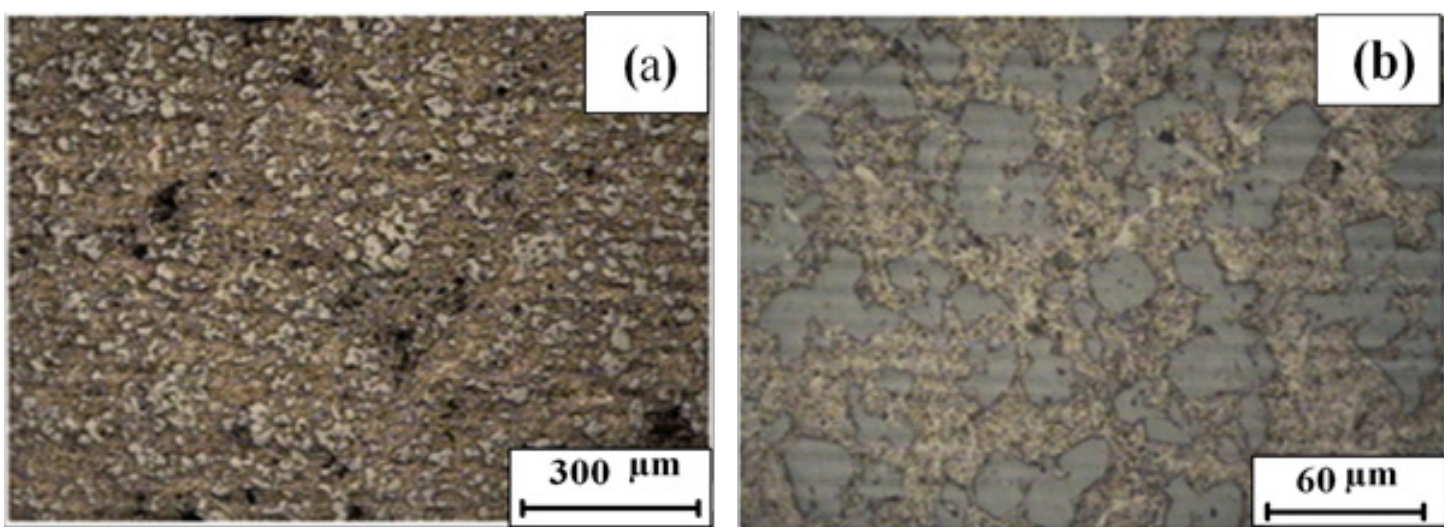

Figure 3: (a) Optical micrograph of SD+HP alloy (b) higher magnification showing the shape and size of primary and eutectic phases.
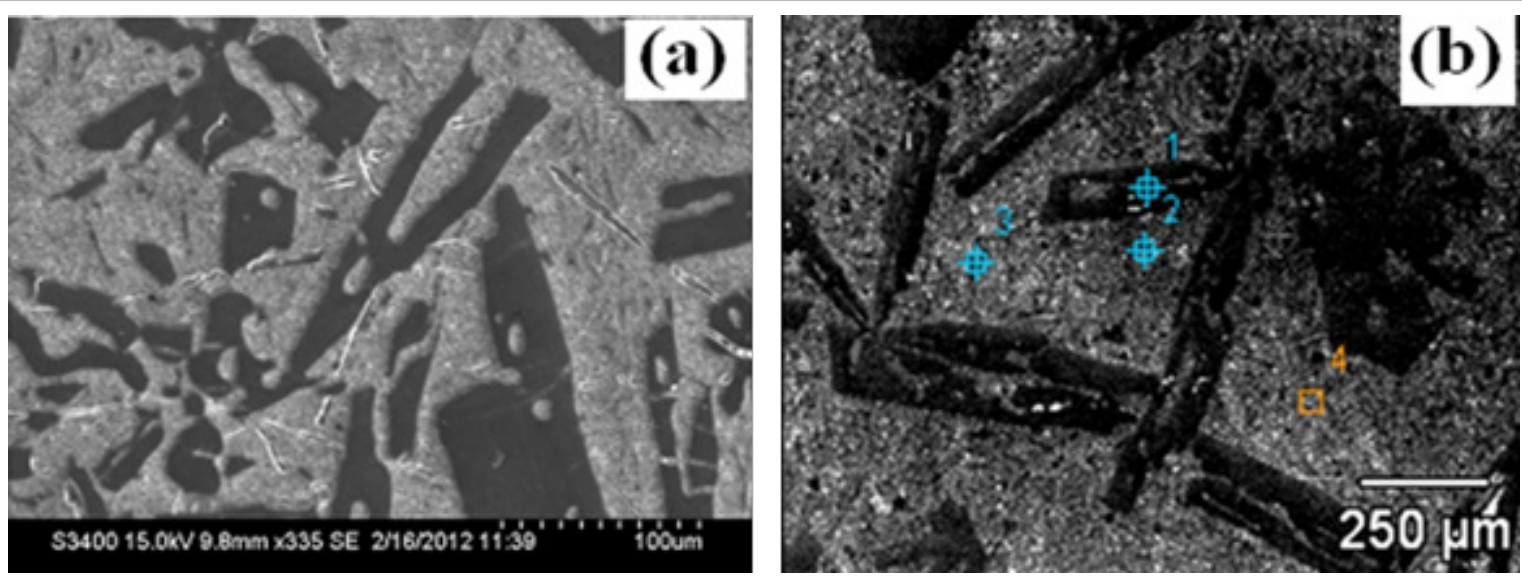

Figure 4: SEM micrograph of as-castAl-35Si alloy (a) SEM and (b) Si phase with EDS points.

Figure 1 shows optical micrographs of as-cast alloy which is composed of coarse plate-like primary Si particles in the size range of $100-550 \mu \mathrm{m}$ and needle/fiber form of eutectic Si. Close analysis of the micrographs shows that the presence of $\mathrm{Al}$ dendrites and the distribution of $\mathrm{Si}$ particles are not uniform throughout. It is also clear from the micrographs that the eutectic Si needle density near the primary Si phase is very low indicating a solute lean area in Si near the primary $\mathrm{Si}$ and matrix interface. It is observed that the primary $\mathrm{Si}$ phase is not blocky but plate-like and is indicative of a tendency of growth in some specific crystallographic direction. A typical microstructural morphology of spray deposited alloy is shown in Figure 2. The alloy consists of primary Si phase having size in the range of $5-12 \mu \mathrm{m}$, eutectic silicon phase seems to be at variance with short and blunted particle structure. The presence of porosity of $13.5 \%$ with spherical morphology is observed in the spray formed alloy. The micrograph of SD+HP alloy is shown 
in the Figure 3. The alloy exhibits the microstructural uniformity, decrease in the average size of Si particle ,increase in the volume fraction of Si phase as a result of the fragmentation of Si particles and also reduced inter particle spacing as well as reduction of volume fraction of porosity due to the plastic shearing deformation of alloy.

SEM microstructure of as-cast alloy is as shown in Figure 4. It consists of coarse, polygonal, plate like structure of primary Si with a eutectic network of Si phases. The SEM/EDS micrograph of ascast alloy (Figure 4(b) reveals the presence of impurity of $\mathrm{Fe}$ in the alloy, the intermetallic $\mathrm{Al}_{5}-\mathrm{Fe}$ phase in the form of sharp needles.
The EDS analysis of phases present in the as-cast alloy is shown in Table 3.

Table 3: EDS analysis of as-cast alloy.

\begin{tabular}{|c|c|c|c|c|c|c|}
\hline Location & Composition & Phase & $\boldsymbol{A l - K}$ & $\boldsymbol{M g}-\boldsymbol{K}$ & $\boldsymbol{S i - K}$ & $\mathbf{F e - K}$ \\
\hline Point 1 & $\mathrm{Si}_{99}$ & $\mathrm{Si}$ & 0.40 & 0.01 & 99.4 & 0.11 \\
\hline Point 2 & $\mathrm{Al}_{95} \mathrm{Si}_{5}$ & $\begin{array}{c}\alpha-\mathrm{Al} \\
\text { Matrix }\end{array}$ & 91.23 & 0.00 & 5.05 & 0.31 \\
\hline Point 3 & $\mathrm{Al}_{81} \mathrm{Fe}_{19}$ & $\begin{array}{c}\alpha-\mathrm{Al} \\
\text { Matrix }\end{array}$ & 81.22 & 0.02 & 0.01 & 18.72 \\
\hline
\end{tabular}
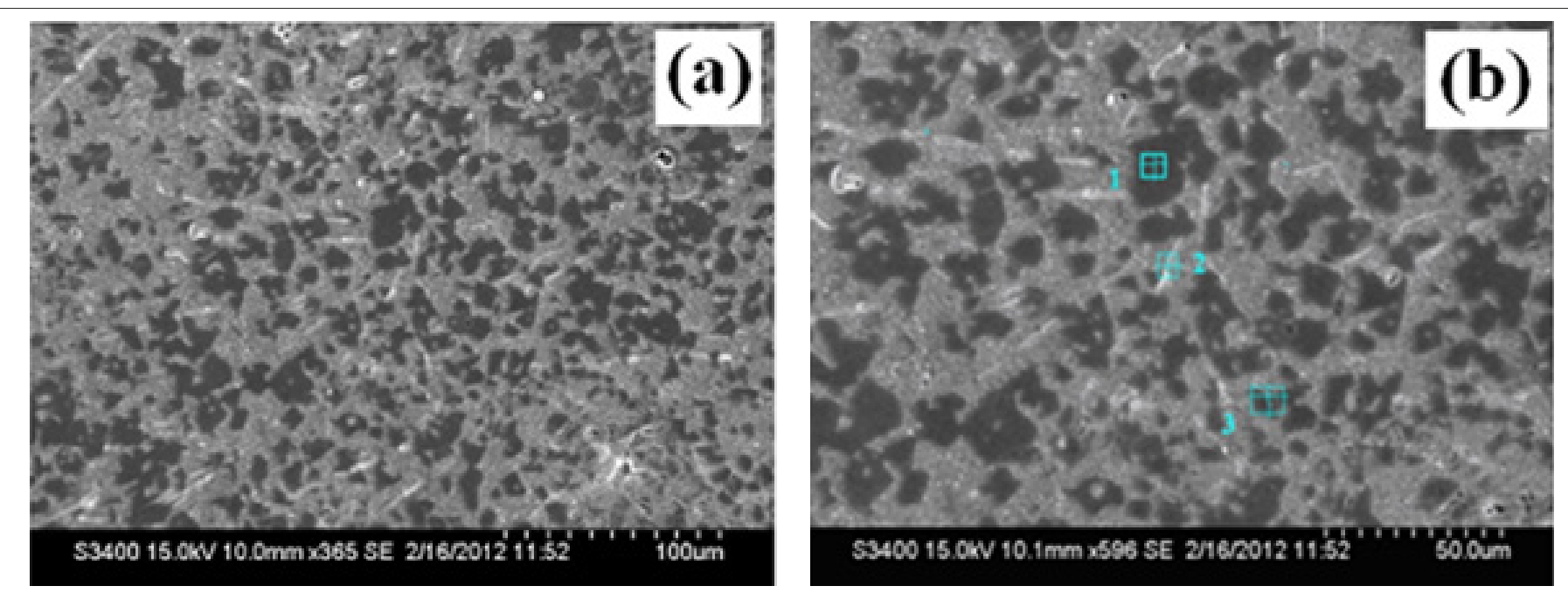

Figure 5: SEM micrograph of spray deposited alloy (a) SEM and (b) Si phase with EDS points

SEM micrograph of SD alloy is as shown in Figure 5. It consists of an agglomerated primary Si particles and iron containing intermetallic phase. It is clearly observed in the SEM /EDS micrograph (Figure 5b) that the primary fine Si particles with a size varying between 10 to $15 \mu \mathrm{m}$ and AlFeSi intermetallic phase with short and blunted needle structure distributed uniformly in the Almatrix. The chemical composition of phases present in the SD alloy is shown Table 4.

Table 4: EDS analysis of spray formed alloy.

\begin{tabular}{|c|c|c|c|c|c|c|c|}
\hline Location & $\begin{array}{c}\text { Composi- } \\
\text { tion }\end{array}$ & Phase & $\boldsymbol{A l - K}$ & $\boldsymbol{M g}-\boldsymbol{K}$ & $\mathbf{S i - K}$ & $\mathbf{F e - K}$ & $\mathbf{0}-\mathbf{K}$ \\
\hline Point 1 & $\mathrm{Si}_{99} \mathrm{Al}_{1}$ & $\mathrm{Si}$ & 1.33 & 0.05 & 98.25 & 0.00 & 0.08 \\
\hline Point 2 & $\mathrm{Al}_{80} \mathrm{Si}_{11} \mathrm{Fe}_{8}$ & $\begin{array}{c}\text { Inter- } \\
\text { metallic }\end{array}$ & 72.47 & 0.15 & 10.38 & 15.83 & 1.15 \\
\hline Point 3 & $\mathrm{Al}_{52} \mathrm{Si}_{48}$ & $\begin{array}{c}\text { Eutectic } \\
\mathrm{Si}\end{array}$ & 44.12 & .0 .15 & 42.18 & 0.47 & 12.3 \\
\hline
\end{tabular}

The microstructure of spray formed, hot-pressed alloy as shown in the Figure 6. It is observed from the figure that there is a significant reduction of porosity level and increase in density after hot pressing of spray formed alloys. Further a finer matrix, fragmentation of Si phase and enhanced density of the alloy.

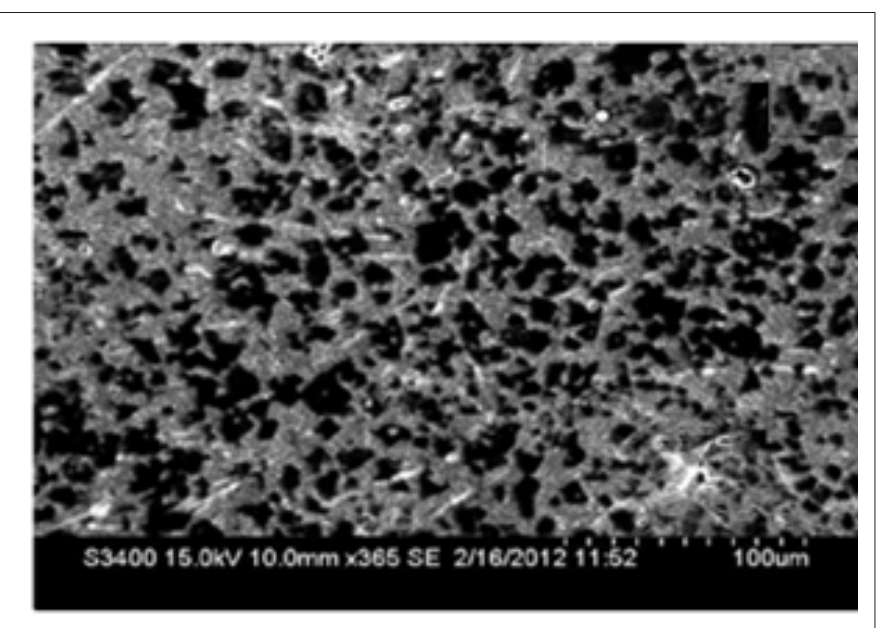

Several investigations have been carried out on the conventional casting of hypereutectic Al-Si alloys. The investigators have demonstrated that slow cooling rate associated with the hypereutectic $\mathrm{Al}-\mathrm{Si}$ alloys by conventional casting method results in a coarse primary Si particle existing either in the form of block, fish bone structure, hopper like, star-like or plate-like structure. While the eutectic Si exhibits the form of acicular, flake, laminar,
Figure 6: SEM micrograph of SD+HP alloy. 
fibrous forms or needle shape [7]. In case of spray formed Al-Si alloy the fine uniform distribution of primary Si particles, eutectic $\mathrm{Si}$ and equiaxial morphology of the $\alpha$-Al phase is a remarkable feature. Due to the relatively high cooling rate of spray deposition process $\left(10^{3}-10^{6} \mathrm{Ks}^{-1}\right)$ and associated repeated deformation, extensive fragmentation and coarsening of partially solidified droplets during the build-up of the deposit effectively alter the morphological stability of the Si phase. During this stage of the process the solid, semi-solid and fully liquid droplets impacting the surface of the deposit provides a large number of fragments that acts as heterogeneous sites for nucleation and growth of further structural features. Thereafter, the nuclei or the other existing fragments grow/coarsen under the vigorous agitation and the cooling conditions in the solidifying layer resulting in an equiaxed structures [8]. The refined microstructure of the spray deposited alloy is also due to the deposition of high velocity semi-solid/ liquid droplets on the substrate giving rise to highly turbulent fluid flow condition in the liquid pool on the growing surface leading to fragmentation of dendrites and other solid phases. The debris created from the dendrite fragmentation leads to a large number of heterogeneous nucleation sites which finally engender the refined microstructure [9]. The amount of gas porosity and interstitial porosity present in the spray deposited materials depends on

Table 5: Micro-hardness of as-cast and SD+HP alloys. thermodynamic properties of the material, atomizing gas and the processing parameters such as melt superheat and flight distance. The binary Al-Si alloys having higher Si content contains higher level of enthalpy. Under similar processing conditions, the spray of hypereutectic Al-Si droplets with a higher level of Si contains a higher fraction of liquid. The hot spray condition is easily formed during spray forming of high Si alloy preform, resulting in larger gas porosity in the alloy [10]. The formation of interstitial porosity is due to the lack of sufficient liquid to fill particle interstices and solidification porosity is significant primarily when excessive liquid is present in the spray upon impingement [11]. The SD+HP alloy lead to the densification, microstructure recovery and recrystallization. This is due to the fragmentation and deformation of coarse brittle Si particles and subsequent realignment around the fine-grained matrix boundaries. In addition to the refinement of grains, hot deformation promotes homogeneous precipitation of hardening particles in Al-matrix [12].

Mechanical properties of SD+HP and as-cast Al-Si alloys Micro hardness: The micro-hardness of as-cast and SD+HP alloys is shown in Table 5. The results show a significant (85\% higher) increase in the microhardness of SD+HP alloy compared to as-cast alloy.

\begin{tabular}{|c|c|c|c|}
\hline Processing route & Phase & Hardness (Hv) & Improvement of hardness (\%) \\
\hline As-cast & eutectic & $69 \pm 1.64$ & $\cdots-$ \\
\hline SD+HP & Bulk & $128 \pm 1.65$ & 85.12 \\
\hline
\end{tabular}

The increase in the hardness of SD+HP alloy is due to the presence of fine and uniform distribution of Si particles in $\mathrm{Al}$ matrix, reduction of porosity. Increase in the volume fraction of the hard Si will lead to higher constraint in the localized deformation of softer matrix under the application of indentation load. The fine primary Si and eutectic Si provide an appreciable impediment to plastic deformation caused by the indentation.

Tensile properties: The tensile properties and the fracture characteristics play a vital role in deciding the suitability of a material for structural applications. The tensile properties depend on the microstructural characteristics and the structural flaws present in the material. The results of tensile studies are shown in the Table 6. It depicts that the as-cast alloy shows ultimate tensile strength and yield strength of 40MPa with elongation of $1.2 \%$ and SD+HP alloy shows an ultimate tensile strength (UTS) of $171 \mathrm{MPa}$ and significant increase in ductility of $6.5 \%$ as compared to the ascast alloy. It is clear from the results of tensile properties that the $\mathrm{SD}+\mathrm{HP}$ alloy is superior to as-cast alloy in terms of improvement in the yield strength, ultimate strength and ductility.

Table 6: Tensile properties of as-cast and SD+HP alloys.

\begin{tabular}{|c|c|c|c|c|}
\hline \multirow{2}{*}{ Alloy composition } & Yield strength (MPa) & UTS (MPa) & Improvement of UTS (\%) & $\begin{array}{c}\text { Elongation } \\
\text { \% }\end{array}$ \\
\hline As-cast Al-35Si & - & 40 & -- & 1.1 \\
\hline SD+HP Al-35Si & 147 & 175 & 337 & 6.5 \\
\hline
\end{tabular}

Fracture surface of tensile specimen: Fracture morphology of $\mathrm{SD}+\mathrm{HP}$ and as-cast alloys is shown in the Figure 7. The fractography of SD+HP alloy show transcrystalline fracture of medium-developed surface, the large regions of the cleavage facets in the Si particles and the brittle eutectic. It seems that the crack front passes in the primary Si crystals by the several cleavage planes without forming visible steps. The fracture surface of as-cast sample exhibit a high degree of brittleness and cracked primary coarse Si particles. This may be attributed to the ability of metallic matrix to deform to extent that the increased number of crack nucleation sites is formed due to increased volume fraction of hard and brittle Si based phases and porosity. 

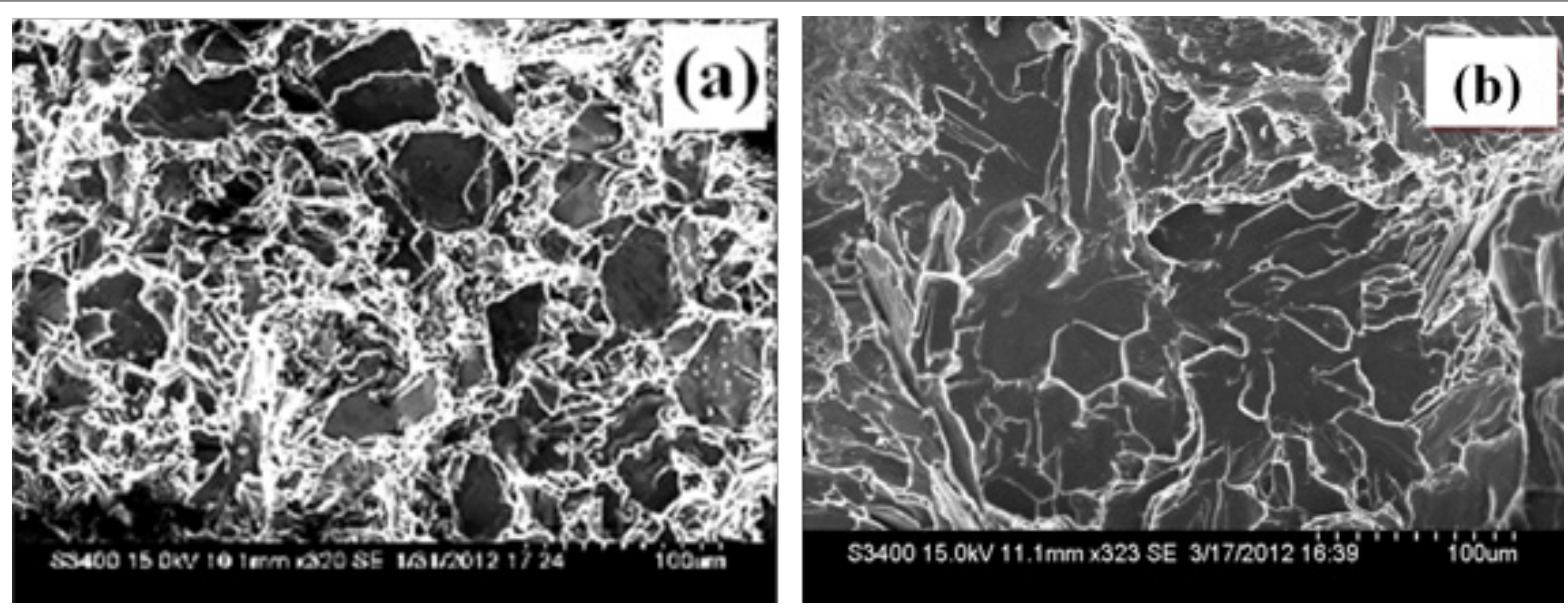

Figure 7: Tensile fracture surfaces of Al-35Si alloys (a) SD+HP and (b) as-cast.

The SD+HP alloy show higher values for yield strength and ultimate strength than that produced by conventional casting. The better tensile properties in SD+HP alloy are attributed to refinement and modification in the microstructure of the alloys during spray deposition process. The fine size and uniform distribution of primary Si phase in the SD+HP alloy give rise to proper interface bonding due to increased surface to volume ratio of Si particulates and therefore improved strength and ductility. Increase in UTS and decrease in ductility in SD+HP alloy may be attributed to the increasing volume fraction of plastically incompatible Si phase in ductile $\mathrm{Al}$ and increase of interface area between primary Si crystals and eutectic matrix with increasing Si content. The increasing volume fraction of plastically incompatible phases decreases the cavitations resistance of the matrix leading to early micro-cracking and hence the reduced ductility under application of tensile loads $[13,14]$.

The low UTS in as-cast alloy is due to the presence of coarse primary Si particles in the form of polyhedral and/or plate-like primary Si particles and plastically incompatible eutectic Si leading to the stress accumulation at the interface with the ductile matrix. The increase in the brittleness is due to the increase in the Si content and formation of micro-cracks /micro-voids under tensile loading [15]. Also, the presence of defects in the as-cast materials leads to weakening of a material by reducing the amount of stress bearing area and therefore lowers the amount of stress the material is able to withstand [16]. The fracture surface of as-cast alloy consists of large proportion of smooth facelets and also show the appearance of cleavage pattern with flat facets representing the Al-Si eutectic zone. In these areas the primary platelet might be torn off from the Al matrix leaving a terrace with a smooth facet. These facets may be formed as a result of fracture of brittle primary Si particles.

\section{Conclusion}

1. Spray forming process is found to be effective in achieving the microstructural refinement. The spray formed Al-35Si alloy consists of primary $\mathrm{Si}$ phase having size varying in the range $5-12 \mu \mathrm{m}$. In contrast, as-cast $\mathrm{Al}-35 \mathrm{Si}$ alloy exhibits the primary $\mathrm{Si}$ particles in the plate-like morphology having size in the range of 50-550 $\mu \mathrm{m}$ and needle/fiber form of eutectic silicon.

2. The spray deposited and hot-pressed exhibits high strength and ductility after hot compression compared to as cast alloy

The fractography of the SD+HP alloy reveals the coexisting facets with underdeveloped dimples suggesting a combined ductile as well as brittle mode of fracture and as-cast alloy failed in brittle mode of fracture.

\section{References}

1. Tenekedjiev N, Gruzleski JE (1990) Hypereutectic aluminum-silicon casting alloys-A review. Cast Metals 39(2): 96-105.

2. Dayanand MG, Alawandi MR, Khaji SH, Rudrakshi GB, Srivastava VC (2018) Comparative study on wear behavior of as cast and spray cast hypereutectic Al-Si Alloy. Journal of Mechanical behavior of materials (JMBM) 28(3): 1-13.

3. Lavernia EJ, Yue Wu (1996) Spray atomization and deposition. John Wiley\& Sons Inc., New York, USA, pp. 487- 489.

4. Grant PS (1995) Spray forming. Journal Progress in Materials Science 39(4): 497-545.

5. Dayanand MG, Raju K, Ojha SN (2015) Influence of Fe addition on wear behavior of spray formed Al-35Si alloy. Transactions of the Indian Institute of Metals, p. 68.

6. ASTM E-112-96 (ASTM, 2003).

7. Barekar NS, Dhindaw BK, Fan Z (2010) Improvement in silicon morphology and mechanical properties of $\mathrm{Al}-17 \mathrm{Si}$ alloy by melt conditioning shear technology. International Journal of Cast Metals Research 23(4): 225-230.

8. Anand S, Srivatsan TS, Yue Wu, Lavernia EJ (1997) Processing, microstructure and fracture behavior of a spray atomized and deposited aluminum-silicon alloy. Journal of Materials Science 329(11): 28352848.

9. Raju K, Harsha AP, Ojha SN. Microstructural features, wear and corrosion behavior of spray cast Al-Si alloy. Proceedings of I. Mech E, Journal of Engineering Technology 225(3): 151-160.

10. Flemings MC (1974) Solidification processing. McGraw-Hill, New York, USA, p. 35. 
11. http://www.astm.org/Standards/B962.htm

12. Nam CV, Han JH, Chung YH, Shin MC (2003) Effect of precipitates on microstructural evolution of $7050 \mathrm{Al}$ alloy sheet during equal channel angular Rolling. Journal of Material Science and Engineering-A, 347(12): 253-257.

13. Gupta M, Ling S (1999) Microstructure and mechanical properties of hypo/ hyper- eutectic Al-Si alloys synthesized using a near-net shape forming technique. Journal of Alloys and Compounds 287: 284-294.
14. Dieter DE(Ed.), (1998) Mechanical metallurgy. McGraw-Hill Book, Singapore, pp. 184-240.

15. Majumdar BS, Pandey AB (2000) Deformation and fracture of a particlereinforced aluminum alloy composite: Part II. Journal of Metallurgical and Materials Transactions A 31(13): 937-950.

16. Payne RD, Moran AL, Cammarata RC (1998) Relating porosity and mechanical properties in spray formed tubular. Journal of Scripta Metall Mater 29(2): 199. 